\title{
Application of an Optimized HPLC Method for the Detection of Various Phenolic Compounds in Apples from Lithuanian Cultivars
}

\author{
Mindaugas Liaudanskas, ${ }^{1}$ Pranas Viškelis, ${ }^{2}$ Valdas Jakštas, ${ }^{1}$ Raimondas Raudonis, ${ }^{1}$ \\ Darius Kviklys, ${ }^{2}$ Arvydas Milašius, ${ }^{1}$ and Valdimaras Janulis ${ }^{1}$ \\ ${ }^{1}$ Department of Pharmacognosy, Faculty of Pharmacy, Lithuanian University of Health Sciences, A. Mickevičiaus Street 9 , \\ LT-44307 Kaunas, Lithuania \\ ${ }^{2}$ Institute of Horticulture, Lithuanian Research Centre for Agriculture and Forestry, Kauno Street 30, Babtai, \\ LT-54333 Kaunas, Lithuania
}

Correspondence should be addressed to Mindaugas Liaudanskas; m.liaudanskas@yahoo.com

Received 23 January 2014; Revised 19 March 2014; Accepted 2 April 2014; Published 24 April 2014

Academic Editor: Maria Luisa Serralheiro

Copyright (c) 2014 Mindaugas Liaudanskas et al. This is an open access article distributed under the Creative Commons Attribution License, which permits unrestricted use, distribution, and reproduction in any medium, provided the original work is properly cited.

\begin{abstract}
A specific analytical procedure including sample preparation and HPLC analysis was developed and validated for the detection of phenolic compounds in the samples of different apples from popular Lithuanian cultivars "Aldas," "Auksis," "Ligol," and "Šampion." The conditions for phenol extraction were optimized: the solvent of the extraction was $70 \%(\mathrm{v} / \mathrm{v})$ ethanol, and the extraction was performed in an ultrasound bath for $20 \mathrm{~min}$ at the temperature of $40^{\circ} \mathrm{C}$. The HPLC mobile phase consisted of $2 \%$ (v/v) acetic acid in water and $100 \%(\mathrm{v} / \mathrm{v})$ acetonitrile. Using the HPLC technique, 11 analytes were identified, and their specificity was confirmed: procyanidin B1, (+)-catechin, chlorogenic acid, procyanidin B2, (-)-epicatechin, rutin, hyperoside, isoquercitrin, avicularin, quercitrin, and phloridzin. Chlorogenic acid was the major component in "Aldas," "Auksis," and "Ligol" and procyanidin B2 in "Šampion." Hyperoside and avicularin were the dominant compounds of all the identified quercetin derivatives in "Aldas" and "Auksis;" hyperoside in "Šampion;" and quercitrin in "Ligol." The total content of phenolic compounds varied from $1641.0 \pm$ $47.9 \mu \mathrm{g} / \mathrm{g}$ (cv. "Ligol”) to $4291.3 \pm 154.2 \mu \mathrm{g} / \mathrm{g}$ (cv. “Aldas").
\end{abstract}

\section{Introduction}

In Lithuania-like in the whole Eastern European regionapples are among the main vegetal food sources rich in phenolic compounds. The Lithuanian Health Program indicates that the nutrition of school-age children should be supplemented with such local vegetal products as apples, carrots, and pears [1]. Using more variable cultivars of fruit in the nutrition of adult and children population is advised. A greater variety of biologically active compounds in fruit is associated with lower mortality [2].

Numerous studies have confirmed the benefit of phenolic compounds for human health. Studies have shown that different groups of phenolic compounds as well as their individual components have a specific effect on different physiological systems. Phenolic compounds in apples have an antiviral effect against Herpes simplex strains and the flu virus $[3,4]$, and they suppress cell proliferation [5], reduce blood levels of triglycerides and low density lipoproteins [6], and thus are useful in the prevention of cancer and cardiovascular diseases. Polyphenolic compounds protect the gastrointestinal mucosa and may be used as a preventive measure against adverse effects of anti-inflammatory drugs [7]. Phenolic compounds in apples may be potentially useful in protecting the lungs against damage from cigarette smoke [8] as well as for the prevention of Alzheimer's disease [9]. Based on these results of scientific studies, it is expedient to concretize the available knowledge about the distribution of phenolic compounds in apples from popular Lithuanian cultivars.

A reliable analytical instrument is required in order to obtain detailed results in the analysis of the phytochemical composition of the apples. The techniques of the qualitative 
and quantitative analyses of the content of phenolic compounds in apples described in literature sources may not always be suitable for implementation in other laboratories. Because of possible differences in the phytochemical composition of the apples, these techniques may be unsuitable for the analysis of local cultivars. Because of this, a detailed scientific analysis requires the redevelopment of sample preparation and mobile phase gradients of the techniques designed in other laboratories. The need for the development of a novel technique was confirmed by our preliminary attempts to adapt the techniques found in scientific literature sources; these attempts did not yield the desired results. For this reason, the aim was set to develop, optimize, and validate the suitable HPLC technique for the detection of phenolic compounds in the lyophilized apple samples of the cultivars "Aldas," "Auksis," "Ligol," and "Šampion" grown in Lithuania.

\section{Materials and Methods}

2.1. Apples. The following apple cultivars were included in the study: "Aldas," "Auksis," "Ligol," and "Šampion;" the apples were harvested in 2011. The apples were supplied by the Institute of Horticulture, Lithuanian Research Centre for Agriculture and Forestry, Babtai, Lithuania $\left(55^{\circ} 60^{\prime} \mathrm{N}, 23^{\circ} 48^{\prime} \mathrm{E}\right)$. The altitude of Babtai town is $57 \mathrm{~m}$ above sea level. The year 2011 was warmer than usual higher; the mean monthly temperatures were higher than the long-term average. The summer of 2011 was distinguished by more rainfall in July and especially in August when double the normal monthly rainfall was recorded. Trees were trained as slender spindle. Pest and disease management was carried out according to the rules of the integrated plant protection. The experimental orchard was not irrigated. Tree fertilization was performed according to soil and leaf analysis. Nitrogen was applied before flowering at the rate of $80 \mathrm{~kg} / \mathrm{ha}$, and potassium was applied after harvest at the rate of $90 \mathrm{~kg} / \mathrm{ha}$. Soil conditions of the experimental orchard were the following: clay loam, pH: 7.3 , humus: $2.8 \%, \mathrm{P}_{2} \mathrm{O}_{5}: 255 \mathrm{mg} / \mathrm{kg}$, and $\mathrm{K}_{2} \mathrm{O}: 230 \mathrm{mg} / \mathrm{kg}$. The apple cultivars "Auksis" (early winter cv., bred in Lithuania), "Šampion" (winter cv., bred in Czech Republic), and "Ligol" (winter cv., bred in Poland) are the main cultivars in Lithuanian commercial orchards. The cv. "Aldas" (early winter cv., bred in Lithuania) is recommended for ecological orchards. Apples were harvested at the optimal harvest time individually established for every cultivar: "Aldas:" 128 DAFB, "Auksis:" 114 DAFB, "Ligol:” 168 DAFB, and “Šampion:” 132 DAFB. The sample size comprised 20 ripe apples of each cultivar.

Each apple was cut into the slices of equal size (up to $1 \mathrm{~cm}$ in thickness), and the stalks and the seeds were removed. The apple slices were immediately frozen in a freezer (at $35^{\circ} \mathrm{C}$ ) with air circulation and then lyophilized with a ZIRBUS sublimator $3 \times 4 \times 5 / 20$ (ZIRBUS technology, Bad Grund, Germany) at the pressure of $0.01 \mathrm{mbar}$ (condenser temperature, $-85^{\circ} \mathrm{C}$ ). The lyophilized apple slices were ground to fine powder by using a Retsch 200 mill (Haan, Germany).

Loss on drying before analysis was determined by drying the apple lyophilizate in a laboratory drying oven to complete evaporation of water and volatile compounds (temperature: $105^{\circ} \mathrm{C}$; the difference in weight between measurements: up to $0.01 \mathrm{~g}$ ) and by calculating the difference in raw material weight before and after drying [10]. The data were recalculated for absolute dry lyophilizate weight.

2.2. Chemicals. All the solvents, reagents, and standards used were of analytical grade. Aluminum trichloride hexahydrate, hexamethylentetramine, acetonitrile, acetone, methanol, and acetic and trifluoroacetic acids were obtained from SigmaAldrich GmbH (Buchs, Switzerland), and ethanol from Stumbras AB (Kaunas, Lithuania). Hyperoside, rutin, quercitrin, phloridzin, procyanidinB1 and procyanidin B2, and chlorogenic acid standards were purchased from Extrasynthese (Genay, France), (+)-catechin and (-)-epicatechin from Fluka (Buchs, Switzerland), and avicularin and isoquercitrin from Chromadex (Santa Ana, USA). In the study, we used deionized water produced by the Crystal E HPLC (Adrona SIA, Riga, Latvia) water purification system.

2.3. Extraction. An amount of $2.5 \mathrm{~g}$ of lyophilized apple powder (exact weight) was weighed, added to $30 \mathrm{~mL}$ of ethanol $(70 \%, v / v)$, and extracted in a Sonorex Digital 10 P ultrasonic bath (Bandelin Electronic GmbH \& Co. KG, Berlin, Germany) for 20 minutes at $40^{\circ} \mathrm{C}$. The conditions of extraction (the type of the extraction, its duration, temperature, and the solvent and its concentration) were chosen considering the results of the optimization of the extraction. The extract obtained was filtered through a paper filter; the apple lyophilizate on the filter was washed twice with $10 \mathrm{~mL}$ of ethanol $(70 \%, \mathrm{v} / \mathrm{v})$ in a $50 \mathrm{~mL}$ flask. The extract was filtered through a membrane filter with a pore size of $0.22 \mu \mathrm{m}$ (Carl Roth GmbH, Karlsruhe, Germany).

2.4. Determination of the Total Flavonoid Content. The total flavonoid content in the extracts of lyophilized apple samples was determined by applying the technique described by Urbonavičiute et al. [11], was calculated using the rutin calibration curve, and was expressed as its equivalent (mg $\mathrm{RE} / \mathrm{g}$ ) for absolute dry lyophilizate weight.

2.5. Instrumentation and Chromatographic Conditions. A Waters 2695 chromatograph equipped with a Waters 2998 PDA detector (Waters, Milford, USA) was used for HPLC analysis. Chromatographic separation was managed, chromatograms were recorded, and data were processed with the Empower v.2.0 software (Waters, Milford, USA). Chromatographic separations were carried out by using a YMC-Pack ODS-A $\left(5 \mu \mathrm{m}, \mathrm{C}_{18}, 250 \times 4.6 \mathrm{~mm}\right.$ i.d. $)$ column equipped with a YMC-Triart $\left(5 \mu \mathrm{m}, \mathrm{C}_{18}, 10 \times 3.0 \mathrm{~mm}\right.$ i.d. $)$ precolumn (YMC Europe GmbH, Dinslaken, Germany). The column was operated at a constant temperature of $25^{\circ} \mathrm{C}$. The volume of the extract being investigated was $10 \mu \mathrm{L}$. The flow rate was $1 \mathrm{~mL} / \mathrm{min}$, and gradient elution was used. The mobile phase consisted of $2 \%(\mathrm{v} / \mathrm{v})$ acetic acid in water (solvent A) and $100 \%(\mathrm{v} / \mathrm{v})$ acetonitrile (solvent B). The following conditions of elution were applied: $0-30$ minutes, $3-15 \% \mathrm{~B}$; 30-45 minutes, $15-25 \% \mathrm{~B}$; $45-50$ minutes, $25-50 \% \mathrm{~B}$; and 
50-55 minutes, $50-95 \%$ B. The total duration of the analysis, including washing and reconditioning of the column, was 70 minutes. The identification of the chromatographic peaks was achieved by comparing the retention times and spectral characteristics $(\lambda=200-600 \mathrm{~nm})$ of the eluting peaks with those of the reference compounds. The compounds identified were confirmed by spiking the sample with the standard compound and monitoring the changes in the peak shape and spectral characteristics. For quantitative analysis, a calibration curve was obtained by the injection of known concentrations of different standard compounds. The concentrations of phenolic compounds identified in the apple extracts were within the limits of the calibration curves. Dihydrochalcones and flavan-3-ols were quantified at $280 \mathrm{~nm}$, phenolic acids at $320 \mathrm{~nm}$, and flavonols at $360 \mathrm{~nm}$.

2.6. Statistical Data Analysis. All the experiments were carried out in triplicate. Means and standard deviations were calculated with SPSS 20.0 software (Chicago, USA). A single factor analysis of variance (ANOVA) along with the posthoc Tukey's test was employed for statistical analysis. The Kolmogorov-Smirnov test was applied to examine the normality of the distribution. To verify the hypothesis about the equality of variances, Levene's test was employed. Differences were considered to be significant at $P<0.05$.

\section{Results and Discussion}

3.1. Optimization of the Extraction Method. The selection of the solvent and the conditions of extraction is an important analytical step in the development of the technique for the qualitative and quantitative analysis of the biologically active compounds in raw plant material. The solvent of the extraction is the main factor in the prognosis of the qualitative and quantitative composition of the isolated phenolic compounds. The extractants most commonly used for the extraction of flavonoid glycosides, their more polar aglycones, and polar phenolic acids are methanol, ethanol, acetone, and their various aqueous mixtures of various concentrations $[12,13]$.

To evaluate the effect of the extractant on the extraction of flavonoids, the lyophilized apple samples were macerated for 4 hours in the dark, and the total content of flavonoids was determined by using spectrophotometry [11]. The extractants selected for the study were methanol, ethanol, and acetone, used at various concentrations. The study showed that $70 \%$ $(\mathrm{v} / \mathrm{v})$ ethanol ensured the highest flavonoid output $(2.7 \pm$ $0.1 \mathrm{mg} \mathrm{RE} / \mathrm{g}$ ) (Figure 1). This extractant was selected for further analysis.

Two techniques ensuring selective extraction of the phenolic compounds from solid-phase samples were chosen for comparative studies of the effectiveness of the extraction techniques: maceration and ultrasound extraction (sonification). During the maceration of the samples at room temperature in dark environment at different time intervals (0.5-24 hours), the highest total flavonoid content $(3.2 \pm 0.1 \mathrm{mg} \mathrm{RE} / \mathrm{g})$ was registered after 24-hour extraction (Figure 2). To evaluate the effectiveness of sonification, apple samples were extracted in an ultrasound bath for 5-90 min at different temperatures

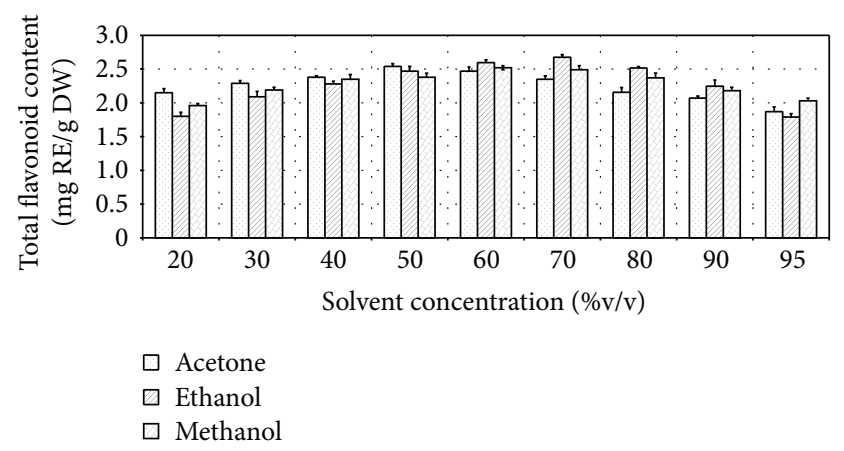

FIGURE 1: The total content of flavonoids in apple samples, using extractants at various concentrations.

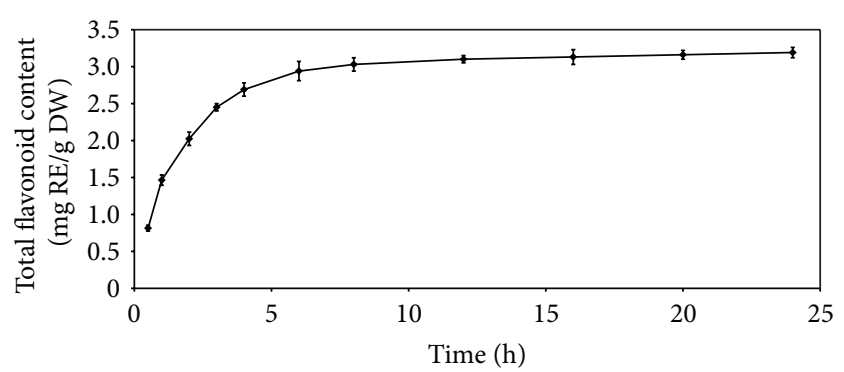

FIgURE 2: The total extracted flavonoid content when macerating apple samples at different time intervals.

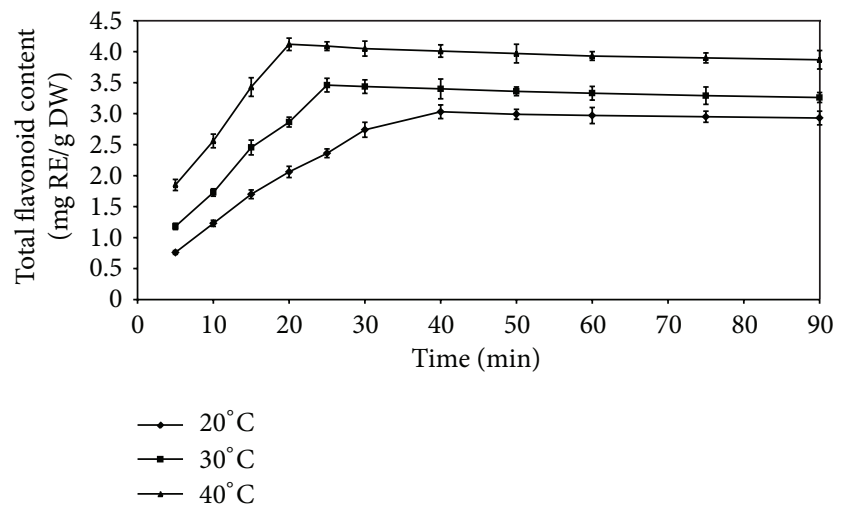

FIGURE 3: The total extracted flavonoid content when extracting apple samples in an ultrasound bath at different time intervals at the temperature of $20-40^{\circ} \mathrm{C}$.

$\left(20-40^{\circ} \mathrm{C}\right)$. The greatest extraction output $(4.1 \pm 0.2 \mathrm{mg} \mathrm{RE} / \mathrm{g})$ was observed after extraction of the apple samples for $20 \mathrm{~min}$ at the temperature of $40^{\circ} \mathrm{C}$ (Figure 3).

The analysis showed that the greatest amount of flavonoids ( $4.1 \pm 0.2 \mathrm{mg} \mathrm{RE} / \mathrm{g})$ from lyophilized apple samples was extracted with $70 \%(\mathrm{v} / \mathrm{v})$ ethanol in an ultrasound bath after 20 minutes of extraction at the temperature of $40^{\circ} \mathrm{C}$. These conditions were selected for further analysis, the extraction from lyophilized samples of different apple cultivars. 
TABLE 1: Characteristics of the quantitative evaluation of phenolic compounds.

\begin{tabular}{|c|c|c|c|c|c|c|}
\hline Compound & $\begin{array}{l}\text { Retention time } \\
(\mathrm{min})^{\mathrm{a}}\end{array}$ & $\begin{array}{l}\text { Wavelength } \\
(\mathrm{nm})\end{array}$ & $\begin{array}{l}\text { Confirmed linearity } \\
\text { range }(\mu \mathrm{g} / \mathrm{mL})\end{array}$ & Calibration equation $^{\mathrm{b}}$ & $\begin{array}{c}\text { Determined } \\
\text { quantitation limit } \\
(\mu \mathrm{g} / \mathrm{mL})\end{array}$ & $R^{2}$ \\
\hline Procyanidin B1 & 15.6 & 280 & $6.25-100$ & $y=7.33 \times 10^{3} x+5.49 \times 10^{3}$ & 2.64 & 0.9998 \\
\hline$(+)$-Catechin & 19.7 & 280 & $5-80$ & $y=7.00 \times 10^{3} x-1.87 \times 10^{3}$ & 2.20 & 0.9999 \\
\hline Chlorogenic acid & 20.7 & 320 & $6.25-100$ & $y=2.68 \times 10^{4} x-3.02 \times 10^{4}$ & 2.93 & 0.9999 \\
\hline Procyanidin B2 & 22.9 & 280 & $6.25-100$ & $y=5.58 \times 10^{3} x+7.15 \times 10^{3}$ & 2.86 & 0.9998 \\
\hline (-)-Epicatechin & 27.3 & 280 & $5-80$ & $y=7.53 \times 10^{3} x+1.19 \times 10^{2}$ & 2.22 & 0.9999 \\
\hline Hyperoside & 40.0 & 360 & $5-80$ & $y=2.23 \times 10^{4} x-1.01 \times 10^{4}$ & 2.42 & 0.9999 \\
\hline Isoquercitrin & 40.1 & 360 & $3.125-50$ & $y=2.66 \times 10^{4} x-2.10 \times 10^{4}$ & 1.54 & 0.9999 \\
\hline Rutin & 39.5 & 360 & $3.125-50$ & $y=1.47 \times 10^{4} x-7.66 \times 10^{3}$ & 2.79 & 0.9998 \\
\hline Quercitrin & 44.5 & 360 & $2.5-40$ & $y=1.77 \times 10^{4} x-5.57 \times 10^{3}$ & 2.19 & 0.9998 \\
\hline Avicularin & 43.9 & 360 & $3.125-50$ & $y=2.32 \times 10^{4} x-1.12 \times 10^{4}$ & 2.56 & 0.9998 \\
\hline Phloridzin & 47.6 & 280 & $3.125-50$ & $y=1.85 \times 10^{4} x-7.09 \times 10^{3}$ & 2.40 & 0.9998 \\
\hline
\end{tabular}

${ }^{a}$ The mean was calculated from 6 replicates.

${ }^{\mathrm{b}} x$ in the calibration equation indicates the concentration of a compound, and $y$ indicates a peak area.

3.2. Development and Optimization of Chromatographic Separation. A broad variety of analytical methods have been employed for the detection of phenolics in raw plant materials and their products. Thin-layer and high-performance thinlayer chromatography, mass, infrared, and ultraviolet spectroscopy, and other analytical methods have been applied for the qualitative analysis of phenolics $[14,15]$. For the quantitative evaluation of phenolic compounds in plant matrices, HPLC and UV-visible absorption spectrophotometry are the most widely used methods; capillary zone electrophoresis is applied less frequently [16].

Experiments during the development stage showed that a better chromatographic separation was achieved by using the YMC-Pack ODS-A column $\left(5 \mu \mathrm{m}, \mathrm{C}_{18}, 250 \times 4.6 \mathrm{~mm}\right.$ i.d. $)$ and selecting acetonitrile rather than methanol as an organic component. For acidification (solvent A), two organic acids were selected: $2 \%$ acetic acid and $0.1 \%$ trifluoroacetic acid. A better separation of the analytes was achieved by using $2 \%$ acetic acid rather than $0.1 \%$ trifluoroacetic acid; therefore, $2 \%$ acetic acid was used for further experiments. The application of acetic acid to acidify the mobile phase has been reported in other studies that investigated phenolic compounds in apples $[3,17,18]$.

The method of gradient elution for the separation of phenolic compounds (quercetin derivatives, flavan-3-ols, phenolic acids, and dihydrochalcones) in ethanol extracts of lyophilized apple samples was optimized. This method allows for an effective separation of phenolic compounds present in lyophilized apple extracts. The elution order of quercetin-3$O$-glycosides - also reported in other studies $[17,19,20]$ - was as follows: quercetin-3-O-rutinoside (rutin), quercetin-3$O$-galactoside (hyperoside), quercetin-3-O-glucoside (isoquercitrin), quercetin-3-O-arabinoside (avicularin), and quercetin-3-O-rhamnoside (quercitrin). The values of resolution (Rs $>2$ ) were achieved in all the samples of standard solutions and extracts. Optimization of the HPLC method allowed for an effective separation of quercetin glycosides: the separation of rutin and hyperoside in ethanol extracts of lyophilized apple samples with the resolution of 2.59; the separation of hyperoside and isoquercitrin with the resolution of 3.12; and the separation of avicularin and quercitrin with the resolution of 2.83 .

The chromatograms of ethanol extracts of apple samples at different wavelengths $(280,320$, and $360 \mathrm{~nm})$ are depicted in Figure 4.

3.3. Validation of the Method. The validation of the method was performed on the basis of the ICH recommendations [21]. The following characteristics of validation were evaluated: the selectivity of the method (specificity), the repeatability of the results (precision), the quantitation limit of the analytes, and linearity.

The evaluation of the selectivity of the method for peak identification and purity was based on the comparison of the retention times and UV spectra of the analytes with those of the standard compounds. The compounds identified were confirmed by adding the standard compound into the analyzed extract and monitoring the changes in the peak shape and spectral characteristics.

The quantitation limit of the analytes was assessed by comparing the peak height to the baseline noise. The ratio of the peak height to baseline noise (signal-to-noise ratio) used for the estimation of the quantitation limit was $10: 1$. The determined quantitation limit varied from $1.54 \mu \mathrm{g} / \mathrm{mL}$ to $2.93 \mu \mathrm{g} / \mathrm{mL}$. The obtained results confirm that this method can be used for the quantitative analysis of phenolic compounds. The estimated determination coefficients $\left(R^{2}\right)$ of calibration curves were greater than 0.999 , and this proves the linearity of the quantitative determination method (Table 1).

The precision of the HPLC method was assessed on the basis of two parameters: repeatability and intermediate precision. The repeatability of the results was evaluated on the basis of the results of consecutive analyses performed 
TABle 2: Precision of the HPLC method for the quantitative evaluation of phenolic compounds.

\begin{tabular}{lccc}
\hline Compound & Intraday $^{\mathrm{a}}$ & $\begin{array}{c}\text { Relative standard deviation (\%) for the peak area } \\
\text { Interday }^{\mathrm{b}}\end{array}$ & $\begin{array}{c}\text { Extraction after extraction } \\
\text { Procyanidin B1 }\end{array}$ \\
(+)-Catechin & 1.32 & 2.39 & 3.77 \\
Chlorogenic acid & 1.49 & 2.26 & 3.56 \\
(-)-Epicatechin & 1.22 & 1.45 & 3.47 \\
Procyanidin B2 & 1.52 & 2.35 & 3.92 \\
Hyperoside & 1.40 & 2.51 & 2.42 \\
Isoquercitrin & 1.38 & 2.61 & 2.77 \\
Rutin & 1.26 & 2.07 & 2.36 \\
Quercitrin & 1.37 & 2.44 & 2.71 \\
Avicularin & 1.46 & 2.54 & 3.27 \\
Phloridzin & 1.42 & 2.60 & 2.52 \\
\hline
\end{tabular}

${ }^{\mathrm{a}}$ Repeatability.

${ }^{\mathrm{b}}$ Intermediate precision.

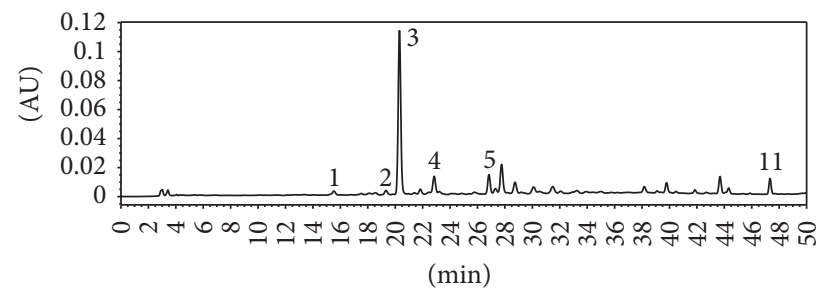

(a)

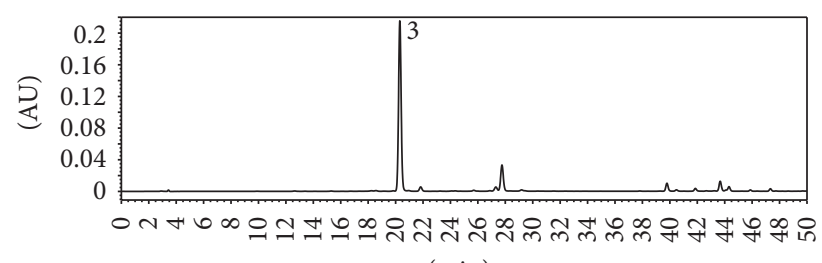

(min)

(b)

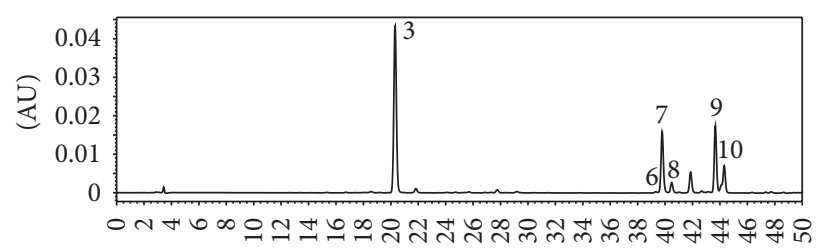

(min)

(c)

Figure 4: Chromatograms of ethanol extracts of the investigated apple samples (cv. "Aldas"): (a) $\lambda=280 \mathrm{~nm}$; (b) $\lambda=320 \mathrm{~nm}$; (c) $\lambda=360 \mathrm{~nm}$. Numbers indicate the peaks of analytes: 1 : procyanidin B1; 2: (+)-catechin; 3: chlorogenic acid; 4: procyanidin B2; 5: (-)epicatechin; 6: rutin; 7: hyperoside; 8: isoquercitrin; 9: avicularin; 10: quercitrin; and 11: phloridzin.

within the same day ( 6 consecutive analyses of a mixture of standards at 3 different concentrations performed within the same day). The percent relative standard deviation (\%RSD) of the repeatability of the method, determined according to the peak area, varied from $1.22 \%$ (chlorogenic acid) to $1.52 \%$ $((-)$-epicatechin). The intermediate precision of the results was assessed based on the results of analyses performed within 3 different days (6 consecutive analyses of a mixture of standards at the mean concentration performed within the same day; 18 analyses in total), and its \%RSD for the peak area varied from $1.45 \%$ (chlorogenic acid) to $2.76 \%$ (phloridzin). Extraction after the extraction of the lyophilized apple sample was performed. A set of 6 ethanol extracts was produced from the same lyophilized apple sample and was analyzed by applying the developed and optimized HPLC method. The estimated \%RSD for the peak area did not exceed 3.92\%. The obtained results describing the precision of developed HPLC method are summarized in Table 2.

\subsection{Identification of Phenolic Compounds in Lyophilized Apple} Samples. Apples are among the most popular fruits consumed worldwide [22]. They is a source of various biologically active substances, especially vitamins and phenolic compounds [23]. Apples contain phenolic compounds of different classes: flavonols (quercetin and isorhamnetin glycosides), dihydrochalcones (phloretin glycosides), flavan3-ols (catechins [monomeric flavan-3-ols] and procyanidins [polymeric flavan-3-ols]), anthocyanins (cyanidin glycosides, especially cyanidin galactoside), and phenolic acids (mostly, chlorogenic acid) [24-26].

Considering the dietary habits of apple consumption, it is relevant to analyze apples without separating their peel from the flesh. As the chemical composition of the apples of different cultivars can vary considerably [26, 27], it is very important to compare and assess the chemical composition of the unpeeled apples of different cultivars and to evaluate their quality, as apples are used in diet, prevention of various diseases, preparation of safe and healthy foods, and development and production of dietary supplements. The above-mentioned circumstances allow for the development of analytical methods and the analysis of apples. 
TABLE 3: Content of phenolic compounds in ethanol extracts obtained from the apples of cultivars grown in Lithuania (expressed for absolute dry lyophilizate weight).

\begin{tabular}{|c|c|c|c|c|}
\hline \multirow{2}{*}{ Compound } & \multicolumn{4}{|c|}{ Amount of phenolic compounds in different cultivars ${ }^{\mathrm{a}}, \mu \mathrm{g} / \mathrm{g}$} \\
\hline & "Aldas" & "Auksis" & "Ligol” & "Šampion" \\
\hline Procyanidin $\mathrm{B} 1$ & $95.7^{\mathrm{a}}$ & $108.1^{\mathrm{b}}$ & $39.6^{c}$ & $83.2^{\mathrm{d}}$ \\
\hline$(+)$-Catechin & $145.7^{\mathrm{a}}$ & $148.2^{\mathrm{b}}$ & $50.1^{\mathrm{c}}$ & $129.7^{\mathrm{d}}$ \\
\hline Chlorogenic acid & $2228.4^{\mathrm{a}}$ & $1618.8^{\mathrm{b}}$ & $687.2^{\mathrm{c}}$ & $341.3^{\mathrm{d}}$ \\
\hline Procyanidin B2 & $658.8^{\mathrm{a}}$ & $454.5^{\mathrm{b}}$ & $320.9^{c}$ & $931.2^{\mathrm{d}}$ \\
\hline$(-)$-Epicatechin & $447.6^{\mathrm{a}}$ & $299.1^{\mathrm{b}}$ & $236.5^{\mathrm{c}}$ & $684.0^{\mathrm{d}}$ \\
\hline Rutin & $16.4^{\mathrm{a}}$ & $12.6^{\mathrm{b}}$ & $14.8^{\mathrm{c}}$ & $12.8^{\mathrm{d}}$ \\
\hline Hyperoside & $191.2^{\mathrm{a}}$ & $52.4^{\mathrm{b}}$ & $68.3^{c}$ & $137.3^{\mathrm{d}}$ \\
\hline Isoquercitrin & $40.3^{\mathrm{a}}$ & $26.2^{\mathrm{b}}$ & $25.7^{\mathrm{c}}$ & $34.1^{\mathrm{d}}$ \\
\hline Avicularin & $194.2^{\mathrm{a}}$ & $58.8^{\mathrm{b}}$ & $52.7^{\mathrm{c}}$ & $81.2^{\mathrm{d}}$ \\
\hline Quercitrin & $130.6^{\mathrm{a}}$ & $44.6^{\mathrm{b}}$ & $76.7^{\mathrm{c}}$ & $70.0^{\mathrm{d}}$ \\
\hline Phloridzin & $142.4^{\mathrm{a}}$ & $90.7^{\mathrm{b}}$ & $68.5^{\mathrm{c}}$ & $63.8^{\mathrm{d}}$ \\
\hline Total & 4291.3 & 2914.0 & 1641.0 & 2568.6 \\
\hline
\end{tabular}

${ }^{a}$ Values are mean $(n=3)$. The different letters indicate significant differences between the values $(P<0.05)$.

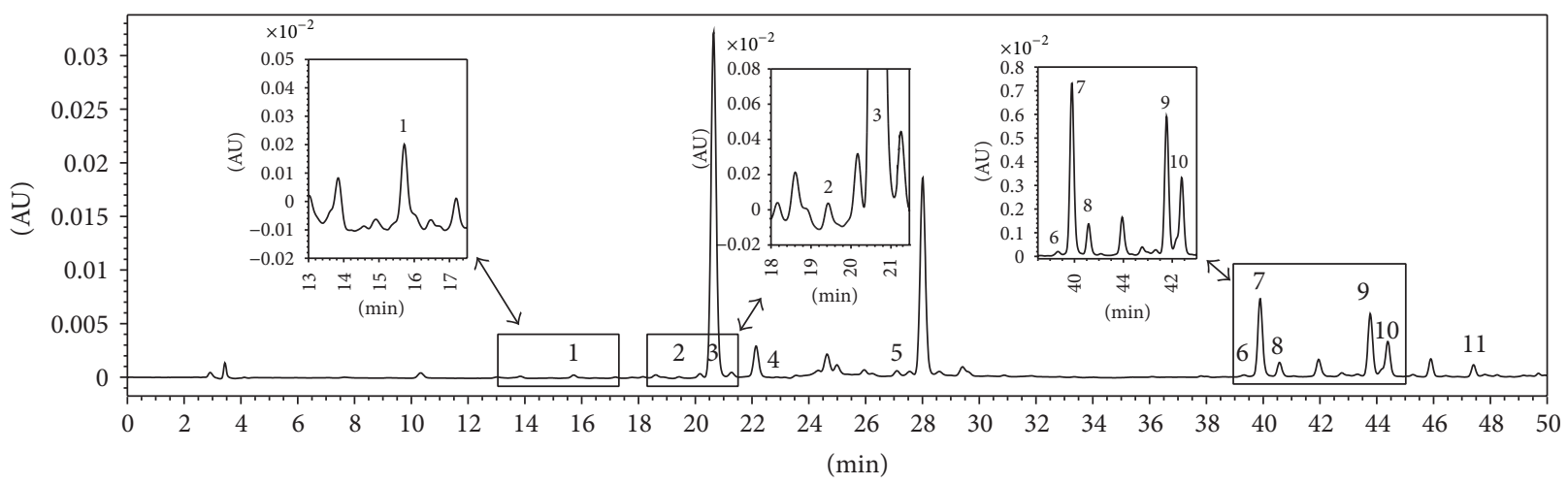

FIGURE 5: Chromatogram of the ethanol extract of the investigated apple fruit sample $(\lambda=320 \mathrm{~nm}, \mathrm{cv}$. "Šampion"). Numbers indicate the peaks of analytes: 1: procyanidin B1; 2: (+)-catechin; 3: chlorogenic acid; 4: procyanidin B2; 5 : (-)-epicatechin; 6: rutin; 7: hyperoside; 8: isoquercitrin; 9: avicularin; 10: quercitrin; and 11: phloridzin.

In this study, the developed, optimized, and validated HPLC method was applied to investigate ethanol extracts of lyophilized apple samples. The content of phenolic compounds in the apples of cultivars "Aldas," "Auksis," "Ligol," and "Šampion" was qualitatively and quantitatively analyzed and determined. An example of the chromatogram of the ethanol extract of the apple fruit sample is shown in Figure 5, and Table 3 summarizes the characteristics of the quantitative content.

The following compounds of different phenolic groups were identified in the investigated ethanol extracts: procyanidin B1, (+)-catechin, chlorogenic acid, procyanidin B2, (-)-epicatechin, rutin, hyperoside, isoquercitrin, avicularin, quercitrin, and phloridzin. Neochlorogenic acid, gallic acid, 5-hydroxymethyl furfural, sinapic acid, isorhamnetin-3-Oglucoside, rosmarinic acid, transcinnamic acid, eupatorin-5methyl ether, sinensetin, and protocatechuic acid in apples or their products were detected by other authors [17, 28-30], but they were not found in the analyzed extracts.

Chlorogenic acid was the major component in the apples of the cultivars "Aldas," "Auksis," and "Ligol." This acid has properties important for human health: antioxidant activity [31], anti-inflammatory activity [32], the reduction of the risk of type 2 diabetes [33], the improvement of cardiovascular function [34], and the inhibition of the processes of carcinogenesis $[35,36]$. The apples of the cv. "Aldas" contained the highest concentration of chlorogenic acid, and it was by 6.5fold greater than that in the apples of the cv. "Šampion" (Table 3 ). The results confirm the findings of other studies indicating that chlorogenic acid in apples is one of the most common phenolic compounds [26,27].

In the studied extracts of apple samples, we detected and quantitatively evaluated monomeric flavan-3-ols: (+)catechin and (-)-epicatechin (Table 3), which together with 
procyanidins may be responsible for the cholesterol lowering [37] and vasodilating [38] effect of the apples; they also inhibit sulfotransferases, thus can regulate the biological activity of hydroxysteroids, and can act as natural chemopreventive agents [39].

The amount of the identified monomeric flavan-3-ols varied from $286.6 \pm 11.4 \mu \mathrm{g} / \mathrm{g}$ (cv. "Ligol") to $813.7 \pm 36.0 \mu \mathrm{g} / \mathrm{g}$ (cv. "Šampion"). The highest concentration of (-)-epicatechin was identified in the apple fruits of the cv. "Šampion." It was by 2.9 -fold greater than its lowest concentration in the apple fruits of the cv. "Ligol." The concentration of (+)-catechin in the apples of the cv. "Auksis" was by 3-fold greater than its lowest concentration in the apples of the cv. "Ligol." Literature reports that apples contain considerably greater amounts of $(-)$-epicatechin than $(+)$-catechin $[23,40]$, and this is in agreement with the results of our study. The ratio of $(+)$ catechin to (-)-epicatechin in the ethanol extracts of different cultivar apple samples varied in the range from 1:2.0 (cv. "Auksis") to 1:5.3 (cv. "Šampion").

Duda-Chodak et al. analyzed the lyophilized apple extracts of the cv. "Šampion" by HPLC. The results of their study showed that the analyzed extracts contained lower amounts of monomeric flavan-3-ols: on the average, $221.7 \mu \mathrm{g} / \mathrm{g}$ of (-)-epicatechin and $12.2 \mu \mathrm{g} / \mathrm{g}$ of (+)-catechin [41]. Different apple cultivation and fertilization approaches could contribute to the differences in their quantitative composition; the impact of meteorological and geographical factors cannot be excluded either.

The compounds of the procyanidin (oligomeric flavan3-ol) class have been identified in the plants of the family Rosaceae[42] and in various apple cultivars [24, 40]. Procyanidins isolated from apples have an antineoplastic effect [43], a strong antioxidant effect [44], an anti-inflammatory effect [45], a cholesterol- and triglyceride-lowering effect [37], and a positive effect on the cardiovascular system [46, 47], and therefore they are among the most promising phenolic compounds in apples. In the present study, procyanidins B1 and B2 were identified and quantified in the ethanol extracts of apple fruit samples. Table 3 shows their quantitative content.

The amount of the identified procyanidins varied from $360.5 \pm 12.6 \mu \mathrm{g} / \mathrm{g}$ (cv. "Ligol") to $1014.4 \pm 43.9 \mu \mathrm{g} / \mathrm{g}$ (cv. "Šampion"). The data in Table 3 show that procyanidin B2 was the major compound in the ethanol extracts of cv. "Šampion" apples, and its concentration was by 2.9 times greater than the lowest concentration of procyanidin B2 found in the ethanol extracts of cv. "Ligol" apple samples. Contrary to other 3 cultivars, procyanidin B2 rather than chlorogenic acid was a dominant compound in the ethanol extracts of cv. "Šampion" apples.

Ethanol extracts of lyophilized apple samples of all the analyzed cultivars contained higher concentrations of procyanidin B2 than those of procyanidin B1 (Table 3). Similar quantitative characteristics of these compounds in the extracts of apple samples have also been found by other researchers $[26,41,48]$. The ratio of procyanidin B1 to procyanidin $\mathrm{B} 2$ in the ethanol extracts of different cultivar apple samples varied in the range from 1:4.2 (cv. "Auksis") to $1: 11.2$ (cv. "Šampion"). These data confirm the importance of the cultivar as a factor for the quantitative composition of apples.

In the investigated ethanol extracts of apple samples, quercetin glycosides were the most abundant group of phenolic compounds. Quercetin glycosides together with compounds of the flavan-3-ol group are most responsible for the antioxidant effect of the complex of phenolic compounds in apples [44]. The consumption of products rich in quercetin glycosides reduces the risk of cancer and neurodegenerative diseases $[49,50]$. Quercetin glycosides inhibit the angiotensin-converting enzyme and therefore have an antihypertensive effect [46].

The following quercetin derivatives were identified and determined quantitatively: rutin, hyperoside, isoquercitrin, avicularin, and quercitrin. The total content of these quercetin glycosides varied from $168.5 \pm 5.0 \mu \mathrm{g} / \mathrm{g}$ (cv. "Auksis") to $532.3 \pm 19.3 \mu \mathrm{g} / \mathrm{g}$ (cv. "Aldas").

The triplet of quercetin glycosides, namely, rutin, hyperoside, and isoquercitrin, where hyperoside was a predominant component and the concentration of rutin was the lowest, was found to be characteristic of all apple cultivars analyzed in our study. This is in line with the results of other studies $[17,20,51]$ and therefore suggests that the rutin-hyperosideisoquercitrin triplet (where hyperoside predominates and the concentration of rutin is relatively low) - along with the compounds of the dihydrochalcone class-could be considered as one of the characteristic features of the phytochemical composition of apples allowing for the identification of apple products.

The rutin-hyperoside-isoquercitrin ratio varied depending on the apple cultivar. It was $1: 11.6: 2.5$ in the ethanol extracts of cv. "Aldas" apples; $1: 4.2: 2.1$-in cv. "Auksis" apples; $1: 4.6$ : 1.7-in cv. "Ligol" apples; and $1: 10.7: 2.7$-in cv. "Šampion" apples.

The data in Table 3 show that the apple samples of the cv. "Aldas" contained the highest levels of all the identified flavonols. The concentration of hyperoside in this cultivar was by 3.7-fold greater than that in the cv. "Auksis." The concentration of isoquercitrin in the apples of the cv. "Aldas" was by 1.6-fold greater than that in the apples of the $\mathrm{cv}$. "Ligol." The concentration of avicularin in the apples of the cv. "Aldas" was by a 3.7-fold higher, compared to the lowest concentration of avicularin found in the apples of the $\mathrm{cv}$. "Ligol." The concentration of quercitrin found in the apples of the cv. "Aldas" was by 2.9 times higher than the lowest concentration of quercitrin in the apples of the cv. "Auksis" (Table 3). In the apples of the cv. "Šampion," hyperoside was the major compound of all quercetin derivatives identified, and this is in line with the results of other studies [41, 48]. Rutin was a minor component among all the identified quercetin derivatives, and these results are consistent with those reported by other authors [20,23]. The highest concentration of rutin $(16.4 \pm 0.7 \mu \mathrm{g} / \mathrm{g})$ was detected in ethanol extracts of the cv. "Aldas" apple samples. This concentration was by 1.3 times greater than the lowest concentration of rutin detected in the ethanol extracts of cv. "Auksis" apple samples. 
Qualitative and quantitative analysis of the compounds of the dihydrochalcone class is of great importance as these compounds can be regarded as chemotaxonomic markers for the identification of apple cultivars as well as products made from apples $[17,52,53]$. Phloridzin exhibits antidiabetic activity $[54,55]$, and therefore apples as plant raw materials accumulating this compound can be potentially useful for the prevention of diabetes mellitus [9]. The highest concentration of dihydrochalcone phloridzin was in the cv. "Aldas" (142.4 \pm $6.3 \mu \mathrm{g} / \mathrm{g}$ ), and it was by 2.3 times higher than the lowest concentration of phloridzin detected in the cv. "Šampion" $(63.8 \pm 2.7 \mu \mathrm{g} / \mathrm{g})$.

Our analysis showed a wide variation in the phenolic content of different apple cultivars grown in Lithuania. The total content of phenolic compounds identified in the ethanol extracts of lyophilized apple samples ranged from $1641.0 \pm$ $47.9 \mu \mathrm{g} / \mathrm{g}$ (cv. "Ligol") to $4291.3 \pm 154.2 \mu \mathrm{g} / \mathrm{g}$ (cv. "Aldas"). The cultivar itself as a factor has an impact on the parameters of qualitative and quantitative content of the apples [20], and depending on the apple cultivar, these parameters can vary considerably [26]. Other factors that may affect the qualitative and quantitative content of apples include the geochemical composition of the soil, the geographic region [41, 5658], and the climatic-meteorological [59] and cultivation or storage conditions $[60,61]$. Some authors found increased levels of phenolic compounds in apple peel due to sunlight exposure $[62,63]$. Orchard fertigation and foliar fertilization lead to increased phenol contents [64]. However, these factors were not considered in this study, and we are planning to include them in our future studies.

\section{Conclusions}

The HPLC-based analytical procedure for the determination of phenolic compounds in the apple samples from 4 popular cultivars was optimized and validated. The specificity, precision, and assaying range confirm the suitability of this method.

The examination of the apple samples revealed the distribution of 11 different groups of phenolic compounds important for human health. Chlorogenic acid was the major component in cultivars "Aldas," "Auksis," and "Ligol" and procyanidin B2 in cv. "Šampion." Hyperoside and avicularin were the dominant compounds among all the identified quercetin derivatives in the apples of the cultivars "Aldas" and "Auksis;" hyperoside in the cv. "Šampion;" and quercitrin in the cv. "Ligol."

\section{Abbreviations}

\section{cv.: Cultivar}

DAFB: Days after full bloom

DW: Dry weight

HPLC: High-performance liquid chromatography

PDA: Photodiode array

RE: Rutin equivalent

\%RSD: Percent relative standard deviation

v/v: Volume/volume.

\section{Conflict of Interests}

The authors declare that there is no conflict of interests regarding the publication of this paper.

\section{Acknowledgments}

This study was supported by the Foundation of the Lithuanian University of Health Sciences and a Grant from the Research Council of Lithuania (no. SVE-02/2011).

\section{References}

[1] Nacionalinès sveikatos tarybos metinis pranešimas. Lietuvos sveikatos programa: rezultatai ir išvados = Annual report of the National Health Board. Lithuanian health program: results and conclusions, Vilnius, Lithuania, 2011.

[2] Food and Heath in Europe: A New Basis for Action, WHO Regional Publications European Series, no. 96, WHO, 2004.

[3] B. Suárez, Á. L. Álvarez, Y. D. García, G. D. Barrio, A. P. Lobo, and F. Parra, "Phenolic profiles, antioxidant activity and in vitro antiviral properties of apple pomace," Food Chemistry, vol. 120, no. 1, pp. 339-342, 2010.

[4] R.-R. He, M. Wang, C.-Z. Wang et al., "Protective effect of apple polyphenols against stress-provoked influenza viral infection in restraint mice," Journal of Agricultural and Food Chemistry, vol. 59, no. 8, pp. 3730-3737, 2011.

[5] S. Reagan-Shaw, D. Eggert, H. Mukhtar, and N. Ahmad, "Antiproliferative effects of apple peel extract against cancer cells," Nutrition and Cancer, vol. 62, no. 4, pp. 517-524, 2010.

[6] S. H. Thilakarathna, H. P. V. Rupasinghe, and P. W. Needs, "Apple peel bioactive rich extracts effectively inhibit in vitro human LDL cholesterol oxidation," Food Chemistry, vol. 138, no. 1, pp. 463-470, 2013.

[7] C. Carrasco-Pozo, H. Speisky, O. Brunser, E. Pastene, and M. Gotteland, "Apple peel polyphenols protect against gastrointestinal mucosa alterations induced by indomethacin in rats," Journal of Agricultural and Food Chemistry, vol. 59, no. 12, pp. 6459-6466, 2011.

[8] M. J. Bao, J. Shen, Y. L. Jia et al., "Apple polyphenol protects against cigarette smoke-induced acute lung injury," Nutrition, vol. 29, no. 1, pp. 235-243, 2013.

[9] A. Francini and L. Sebastiani, "Phenolic compounds in apple (Malus x domestica Borkh.): compounds characterization and stability during postharvest and after processing," Antioxidants, vol. 2, no. 3, pp. 181-193, 2013.

[10] European Pharmacopoeia, vol. 1, Council of Europe, Strasbourg, France, 7th edition, 2010.

[11] A. Urbonavičiute, V. Jakštas, O. Kornyšova, V. Janulis, and A. Maruška, "Capillary electrophoretic analysis of flavonoids in single-styled hawthorn (Crataegus monogyna Jacq.) ethanolic extracts," Journal of Chromatography A, vol. 1112, no. 1-2, pp. 339-344, 2006.

[12] C. Santos-Buelga, S. Gonzalez-Manzano, M. Dueñas, and A. M. Gonzalez-Paramas, "Extraction and isolation of phenolic compounds," Methods in Molecular Biology, vol. 864, pp. 427464, 2012.

[13] A. Khoddami, M. A. Wilkes, and T. H. Roberts, “Techniques for analysis of plant phenolic compounds," Molecules, vol. 18, no. 2, pp. 2328-2375, 2013. 
[14] C. D. Stalikas, "Extraction, separation, and detection methods for phenolic acids and flavonoids," Journal of Separation Science, vol. 30, no. 18, pp. 3268-3295, 2007.

[15] M. Naczk and F. Shahidi, "Extraction and analysis of phenolics in food," Journal of Chromatography A, vol. 1054, no. 1-2, pp. 95111, 2004.

[16] R. Tsao and Z. Deng, "Separation procedures for naturally occurring antioxidant phytochemicals," Journal of Chromatography B, vol. 812, no. 1-2, pp. 85-99, 2004.

[17] A. Schieber, P. Keller, and R. Carle, "Determination of phenolic acids and flavonoids of apple and pear by high-performance liquid chromatography," Journal of Chromatography A, vol. 910, no. 2, pp. 265-273, 2001.

[18] N.-N. Chen, S.-C. Zhao, L.-G. Deng et al., "Determination of five polyphenols by HPLC/DAD and discrimination of apple varieties," Chromatographia, vol. 73, no. 5-6, pp. 595-598, 2011.

[19] R. Tsao, R. Yang, J. C. Young, and H. Zhu, "Polyphenolic profiles in eight apple cultivars using high-performance liquid chromatography (HPLC)," Journal of Agricultural and Food Chemistry, vol. 51, no. 21, pp. 6347-6353, 2003.

[20] S. C. Marks, W. Mullen, and A. Crozier, "Flavonoid and chlorogenic acid profiles of English cider apples," Journal of the Science of Food and Agriculture, vol. 87, no. 4, pp. 719-728, 2007.

[21] N. Baber, "International conference on harmonisation of technical requirements for registration of pharmaceuticals for human use (ICH)," British Journal of Clinical Pharmacology, vol. 37, no. 5, pp. 401-404, 1994.

[22] A. Mari, I. Tedesco, A. Nappo, G. L. Russo, A. Malorni, and V. Carbone, "Phenolic compound characterisation and antiproliferative activity of "Annurca" apple, a southern Italian cultivar," Food Chemistry, vol. 123, no. 1, pp. 157-164, 2010.

[23] J. Wu, H. Gao, L. Zhao et al., "Chemical compositional characterization of some apple cultivars," Food Chemistry, vol. 103, no. 1, pp. 88-93, 2007.

[24] L. Montero, M. Herrero, E. Ibáñez, and A. Cifuentes, "Profiling of phenolic compounds from different apple varieties using comprehensive two-dimensional liquid chromatography," Journal of Chromatography A, vol. 1313, pp. 275-283, 2013.

[25] D. De Paepe, K. Servaes, B. Noten et al., "An improved mass spectrometric method for identification and quantification of phenolic compounds in apple fruits," Food Chemistry, vol. 136, no. 2, pp. 368-375, 2013.

[26] M. Ceymann, E. Arrigoni, H. Schärer, A. Bozzi Nising, and R. F. Hurrell, "Identification of apples rich in health-promoting flavan-3-ols and phenolic acids by measuring the polyphenol profile," Journal of Food Composition and Analysis, vol. 26, no. 1-2, pp. 128-135, 2012.

[27] L. Jakobek, R. García-Villalba, and F. A. Tomás-Barberán, "Polyphenolic characterisation of old local apple varieties from Southeastern European region," Journal of Food Composition and Analysis, vol. 31, no. 2, pp. 199-211, 2013.

[28] M. C. Soares, É. T. Ribeiro, E. M. Kuskoski et al., "Composition of phenolic acids content in apple (Malus sp) pomace," Semina:Ciencias Agrarias, vol. 29, no. 2, pp. 339-348, 2008.

[29] A. Schieber, P. Keller, P. Streker, I. Klaiber, and R. Carle, "Detection of isorhamnetin glycosides in extracts of apples (Malus domestica cv. "Brettacher") by HPLC-PDA and HPLCAPCI-MS/MS," Phytochemical Analysis, vol. 13, no. 2, pp. 87-94, 2002.
[30] M. Amzad Hossain, S. M. Salehuddin, M. J. Kabir, S. M. M. Rahman, and H. P. V. Rupasinghe, "Sinensetin, rutin, 3/hydroxy-5, 6, 7, 4/-tetramethoxyflavone and rosmarinic acid contents and antioxidative effect of the skin of apple fruit," Food Chemistry, vol. 113, no. 1, pp. 185-190, 2009.

[31] Y. Sato, S. Itagaki, T. Kurokawa et al., "In vitro and in vivo antioxidant properties of chlorogenic acid and caffeic acid," International Journal of Pharmaceutics, vol. 403, no. 1-2, pp. 136138, 2011.

[32] X. Zhang, H. Huang, T. Yang et al., "Chlorogenic acid protects mice against lipopolysaccharide-induced acute lung injury," Injury, vol. 41, no. 7, pp. 746-752, 2010.

[33] T. Thomas and A. F. H. Pfeiffer, "Foods for the prevention of diabetes: how do they work?" Diabetes/Metabolism Research and Reviews, vol. 28, no. 1, pp. 25-49, 2012.

[34] Y. Kanno, R. Watanabe, H. Zempo, M. Ogawa, J. Suzuki, and M. Isobe, "Chlorogenic acid attenuates ventricular remodeling after myocardial infarction in mice," International Heart Journal, vol. 54, no. 3, pp. 176-180, 2013.

[35] N. Cinkilic, S. K. Cetintas, T. Zorlu et al., "Radioprotection by two phenolic compounds: chlorogenic and quinic acid, on $\mathrm{X}$-ray induced DNA damage in human blood lymphocytes in vitro," Food and Chemical Toxicology, vol. 53, pp. 359-363, 2013.

[36] B. Stefanska, H. Karlic, F. Varga, K. Fabianowska-Majewska, and A. G. Haslberger, "Epigenetic mechanisms in anti-cancer actions of bioactive food components-the implications in cancer prevention," British Journal of Pharmacology, vol. 167, no. 2, pp. 279-297, 2012.

[37] A. T. Serra, J. Rocha, B. Sepodes et al., "Evaluation of cardiovascular protective effect of different apple varieties-correlation of response with composition," Food Chemistry, vol. 135, no. 4, pp. 2378-2386, 2012.

[38] B. A. R. Lina, A. A. Reus, O. Hasselwander, Q. Bui, and P. P. Tenning, "Safety evaluation of EvesseTM EPC, an apple polyphenol extract rich in flavan-3-ols," Food and Chemical Toxicology, vol. 50, no. 8, pp. 2845-2853, 2012.

[39] C. Huang, Y. Chen, T. Zhou, and G. Chen, "Sulfation of dietary flavonoids by human sulfotransferases," Xenobiotica, vol. 39, no. 4, pp. 312-322, 2009.

[40] L. Panzella, M. Petriccione, P. Rega, M. Scortichini, and A. Napolitano, "A reappraisal of traditional apple cultivars from Southern Italy as a rich source of phenols with superior antioxidant activity," Food Chemistry, vol. 140, no. 4, pp. 672679, 2013.

[41] A. Duda-Chodak, T. Tarko, P. Satora, P. Sroka, and T. Tuszyński, "The profile of polyphenols and antioxidant properties of selected apple cultivars grown in Poland," Journal of Fruit and Ornamental Plant Research, vol. 18, no. 2, pp. 39-50, 2010.

[42] M. Bräunlich, R. Slimestad, H. Wangensteen et al., "Extracts, anthocyanins and procyanidins from Aronia melanocarpa as radical scavengers and enzyme inhibitors," Nutrients, vol. 5, no. 3, pp. 663-678, 2013.

[43] M. E. Maldonado-Celis, S. Bousserouel, F. Gossé, A. Lobstein, and F. Raul, "Apple procyanidins activate apoptotic signaling pathway in human colon adenocarcinoma cells by a lipid-raft independent mechanism," Biochemical and Biophysical Research Communications, vol. 388, no. 2, pp. 372-376, 2009.

[44] X. Bai, H. Zhang, and S. Ren, "Antioxidant activity and HPLC analysis of polyphenol-enriched extracts from industrial apple pomace," Journal of the Science of Food and Agriculture, vol. 93, no. 10, pp. 2502-2506, 2013. 
[45] C. M. Andre, J. M. Greenwood, E. G. Walker et al., "Antiinflammatory procyanidins and triterpenes in 109 apple varieties," Journal of Agricultural and Food Chemistry, vol. 60, no. 42, pp. 10546-10554, 2012.

[46] N. Balasuriya and H. P. V. Rupasinghe, "Antihypertensive properties of flavonoid-rich apple peel extract," Food Chemistry, vol. 135, no. 4, pp. 2320-2325, 2012.

[47] E.-B. Byun, S. Korematsu, T. Ishikawa et al., "Apple procyanidins induce hyperpolarization of rat aorta endothelial cells via activation of $\mathrm{K}^{+}$channels," Journal of Nutritional Biochemistry, vol. 23, no. 3, pp. 278-286, 2012.

[48] A. Duda-Chodak, T. Tarko, and T. Tuszyński, "Antioxidant activity of apples-an impact of maturity stage and fruit part," Acta Scientiarum Polonorum, Technologia Alimentaria, vol. 10, no. 4, pp. 443-454, 2011.

[49] F. Dajas, "Life or death: neuroprotective and anticancer effects of quercetin," Journal of Ethnopharmacology, vol. 143, no. 2, pp. 383-396, 2012.

[50] M. González-Vallinas, M. González-Castejón, A. RodríguezCasado, and A. Ramírez de Molina, "Dietary phytochemicals in cancer prevention and therapy: a complementary approach with promising perspectives," Nutrition Reviews, vol. 71, no. 9, pp. 585-599, 2013.

[51] A. Alberti, A. A. F. Zelinski, D. M. Zardo, I. M. Demiate, A. Nogueira, and L. I. Mafra, "Optimisation of the extraction of phenolic compounds from apples using response surface methodology," Food Chemistry, vol. 149, pp. 151-158, 2014.

[52] R. M. Alonso-Salces, K. Ndjoko, E. F. Queiroz et al., "On-line characterisation of apple polyphenols by liquid chromatography coupled with mass spectrometry and ultraviolet absorbance detection," Journal of Chromatography A, vol. 1046, no. 1-2, pp. 89-100, 2004.

[53] C. Gosch, H. Halbwirth, and K. Stich, "Phloridzin: biosynthesis, distribution and physiological relevance in plants," Phytochemistry, vol. 71, no. 8-9, pp. 838-843, 2010.

[54] M. Kobori, S. Masumoto, Y. Akimoto, and H. Oike, "Phloridzin reduces blood glucose levels and alters hepatic gene expression in normal BALB/c mice," Food and Chemical Toxicology, vol. 50, no. 7, pp. 2547-2553, 2012.

[55] M. Najafian, M. Z. Jahromi, M. J. Nowroznejhad et al., "Phloridzin reduces blood glucose levels and improves lipids metabolism in streptozotocin-induced diabetic rats," Molecular Biology Reports, vol. 39, no. 5, pp. 5299-5306, 2012.

[56] E. Delian, V. Petre, I. Burzo, L. Bǎdulescu, and D. Hoza, "Total phenols and nutrients composition aspects of some apple cultivars and new studied breeding creations lines grown in Voineşti area-Romania," Romanian Biotechnological Letters, vol. 16, no. 6, pp. 6722-6729, 2011.

[57] M. A. Awad and A. De Jager, "Relationships between fruit nutrients and concentrations of flavonoids and chlorogenic acid in "Elstar" apple skin," Scientia Horticulturae, vol. 92, no. 3-4, pp. 265-276, 2002.

[58] T. K. McGhie, M. Hunt, and L. E. Barnett, "Cultivar and growing region determine the antioxidant polyphenolic concentration and composition of apples grown in New Zealand," Journal of Agricultural and Food Chemistry, vol. 53, no. 8, pp. 3065-3070, 2005.

[59] L. Mainla, U. Moor, K. Karp, and T. Püssa, "The effect of genotype and rootstock on polyphenol composition of selected apple cultivars in Estonia," Zemdirbyste, vol. 98, no. 1, pp. 63-70, 2011.
[60] N. T. T. Hoang, J. B. Golding, and M. A. Wilkes, “The effect of postharvest 1-MCP treatment and storage atmosphere on "Cripps Pink" apple phenolics and antioxidant activity," Food Chemistry, vol. 127, no. 3, pp. 1249-1256, 2011.

[61] A. A. Van der Sluis, M. Dekker, A. De Jager, and W. M. F. Jongen, "Activity and concentration of polyphenolic antioxidants in apple: effect of cultivar, harvest year, and storage conditions," Journal of Agricultural and Food Chemistry, vol. 49, no. 8, pp. 3606-3613, 2001.

[62] S. F. Hagen, G. I. A. Borge, G. B. Bengtsson et al., "Phenolic contents and other health and sensory related properties of apple fruit (Malus domestica Borkh., cv. Aroma): effect of postharvest UV-B irradiation," Postharvest Biology and Technology, vol. 45, no. 1, pp. 1-10, 2007.

[63] S. Sun, L. Xin, H. Gao, J. Wang, and P. Li, "Response of phenolic compounds in "Golden Delicious" and "Red Delicious" apples peel to fruit bagging and subsequent sunlightre-exposure," Scientia Horticulturae, vol. 168, pp. 161-167, 2014.

[64] S. Murtić, H. Čivić, M. Đurić et al., "The content of some antioxidants in apple depends on the type of fertilization," Polish Journal of Environmental Studies, vol. 22, no. 2, pp. 475-480, 2013. 

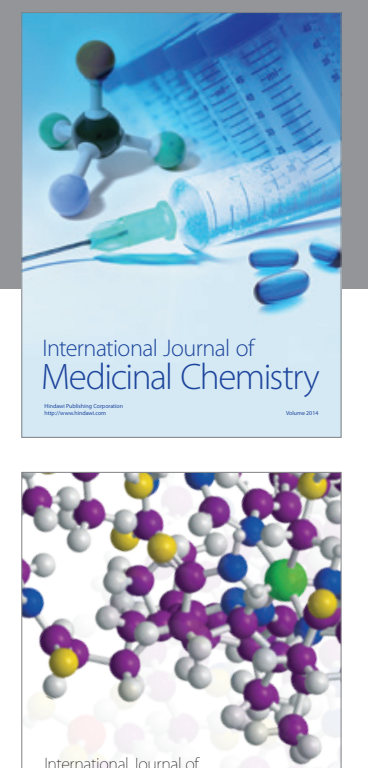

\section{Carbohydrate} Chemistry

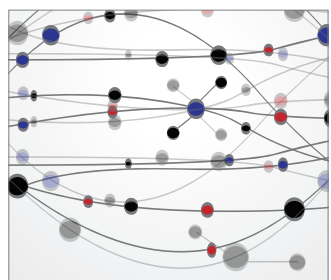

The Scientific World Journal
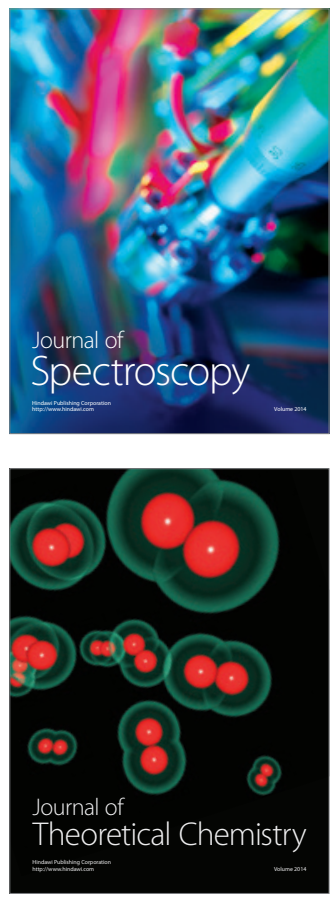
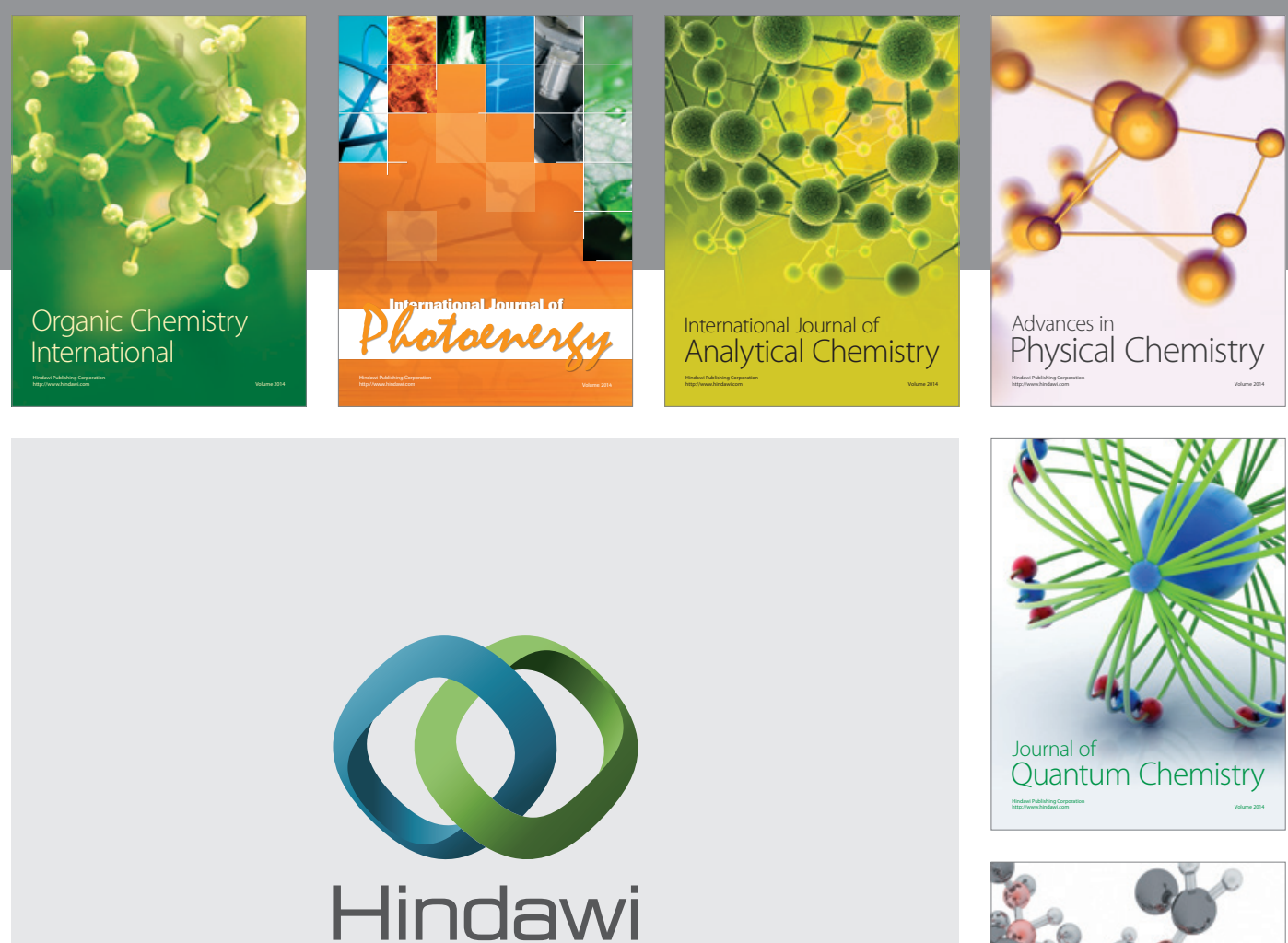

Submit your manuscripts at

http://www.hindawi.com

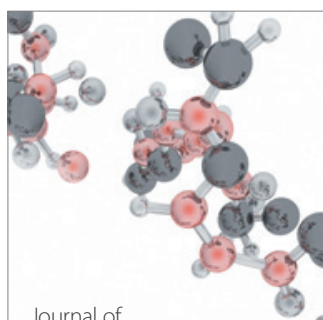

Analytical Methods

in Chemistry

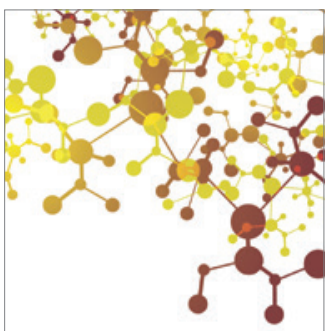

Journal of

Applied Chemistry

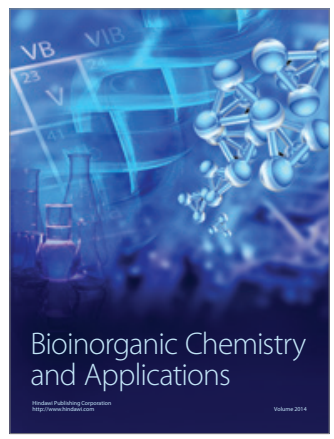

Inorganic Chemistry
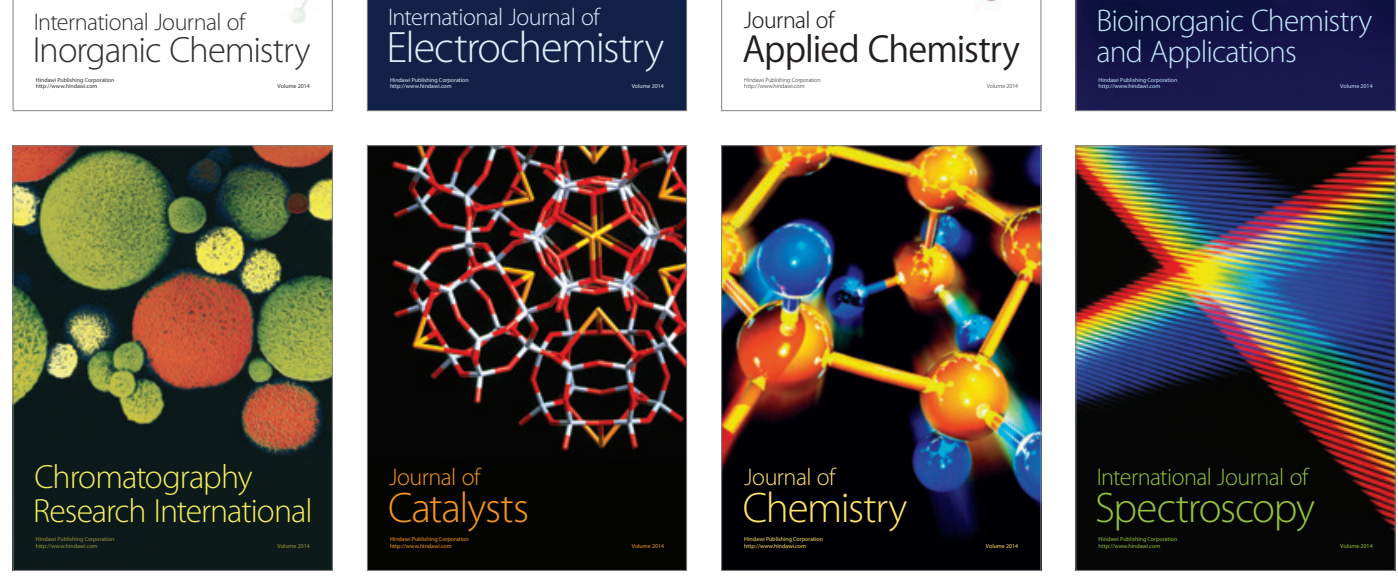